\title{
Exploration of PBL combined with Standardized Patient in the Teaching of
}

\section{Ophthalmology}

\author{
Yan Jin \\ Ophthalmology Medical Teaching and Research Section \\ Xi'an Medical University, \\ Xi'an 710021, Shaanxi, China \\ e-mail: yanjin26@126.com

\section{Ding Li} \\ Ophthalmology Medical Teaching and Research Section \\ Xi'an Medical University, \\ Xi'an 710021, Shaanxi, China \\ e-mail: 370486946@qq.com
}

\begin{abstract}
In order to investigate the effect of PBL (problem-based learning) combined with standardized patient in the teaching of ophthalmology, 64 students were divided randomly into experimental $\operatorname{group}(n=32)$ and control $\operatorname{group}(n=32)$. Traditional teaching method was implemented in control group while PBL combined with SP was applied in experimental group. At the end of term students were interviewed using self-administered questionnaire to obtain their evaluation for teaching effect. Enumeration data were analyzed by $\chi^{2}$ test. Measurement data were expressed as $\bar{x} \pm s$ and analyzed by independent samples $t$ test. $P<0.05$ signifies statistical differences. The students in experimental group had a significantly better self-assessment than the control group in learning enthusiasm, consciousness of team cooperation, comprehensive analysis ability, self-learning ability, innovation ability and practice ability.
\end{abstract}

Keywords-PBL; Standardized Patient; Ophthalmology; Education Reform

\section{INTRODUCTION}

As a modern pedagogical philosophy, problem-based learning $(\mathrm{PBL})$ is increasingly being recognized as a major

\author{
Wang Li \\ Ophthalmology Medical Teaching and Research Section \\ Xi'an Medical University, \\ Xi'an 710021, Shaanxi, China \\ Wang Junjie \\ Ophthalmology Medical Teaching and Research Section \\ Xi'an Medical University, \\ Xi'an 710021, Shaanxi, China
}

research area in student learning and pedagogical innovation in health sciences education. [1]. PBL aims to promote active engagement of students in their own learning by stimulating constructive, self-directed, collaborative and contextual learning and by using (patient) problems as triggers of learning [2].Since the introduction of simulated patients (SPs) by Barrows in 1964, SPs have been used extensively in medical education and assessment[3]. SPs are healthy person with system training or mild patients, who can accurately simulate the patient's clinical history, symptoms, signs [ 4,5].

The aim of our study was to compare the teaching effects and learning outcomes of PBL combined with SPs curriculum and traditional curriculum in ophthalmology, now report as follows.

\section{METHODS}

This was a study of Xi'an Medical University of Optometry undergraduate students of 2014 (N=64). 32 students in the experiment group (group A) was randomly selected, and the teaching method of PBL combined with Sps was adopted. The other 32 students were the control 
group (group B), and the traditional teaching method was adopted.

Teachers wrote the PBL teaching case for each section in reference to the typical clinical cases. The teacher served as the SPs and prepared the relevant inspection data. The students in group A were free to form a study group and carried out PBL in groups. According to the specific content of each chapter, the SPs who were simulated by teachers and students' group constituted the clinical treatment scenes. The SPs were asked by the students to got the main complaint, the current history and the results of the examination. Based on the results of questions about SPs, each group learned the content of this chapter and then discussed it. After the discussion, each group reported the results of the study and explained the unsolved questions in the study. Finally, the teacher answered students' questions and helped students to form a complete knowledge system(Chart 1). Teachers used traditional teaching methods to teach group $\mathrm{B}$.

The results of theoretical examination, practical examination and questionnaires were used to evaluate the teaching effects of the two groups. A five-item survey which asking for students' Personal opinion about the case was administered to all the students.

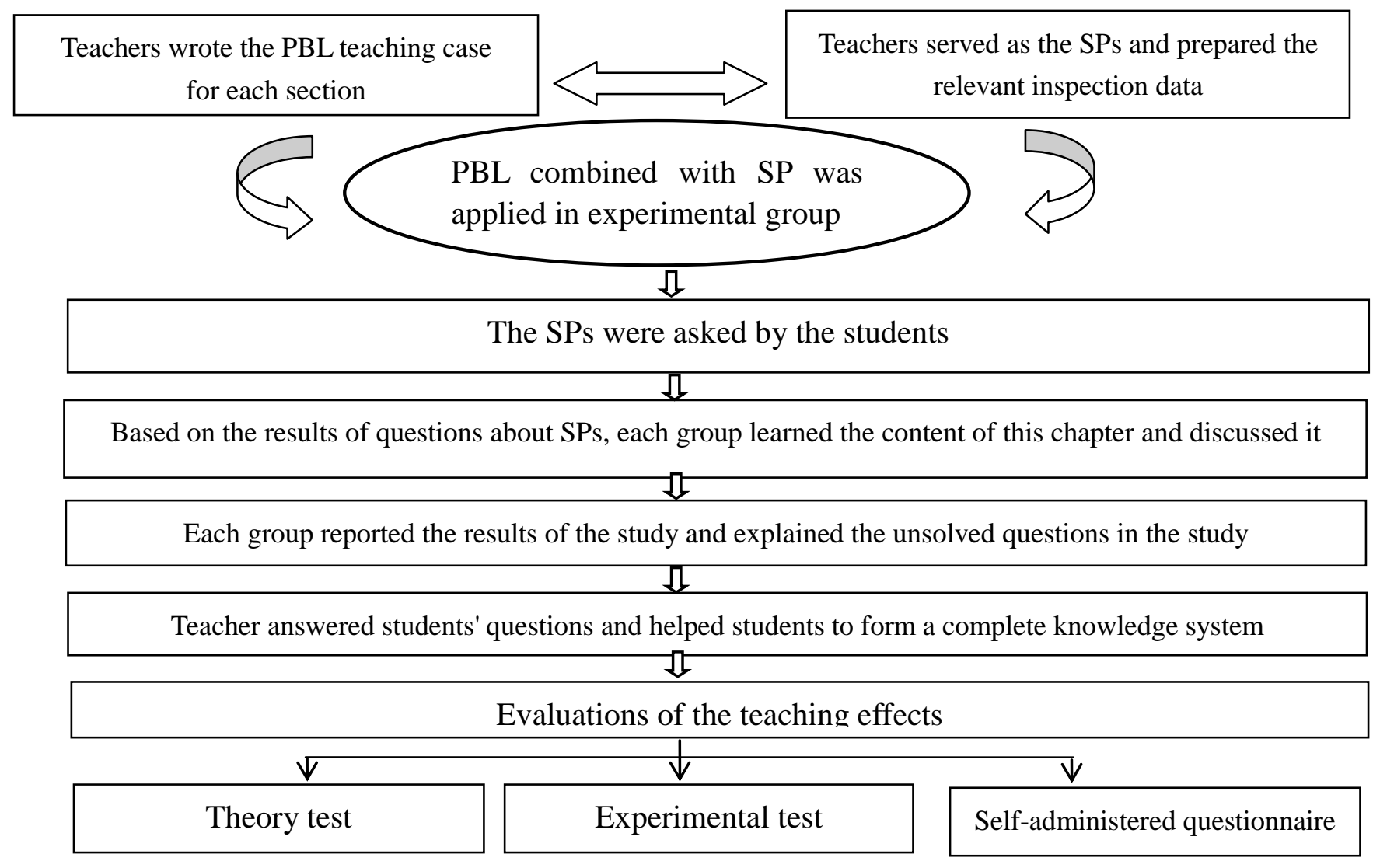

Figure 1. Chart 1 Teaching method of group A

The Pearson chi-2 test was used to compare the results of the questionnaire survey. The comparison of measurement data were compared using two independent sample $t$ test for statistical analysis. $\mathrm{P}<0.05$ was considered to be statistically significant.

\section{RESULTS}

There were no statistically significant differences between the two groups $(\mathrm{P}>0$. 05) in demographic variables(such as age, gender)and basic courses' score.

In the quantitative outcomes, Students in the group A reported significantly higher mean scores across the four 
texts' outcomes than students in group $\mathrm{B}$ (Table 1). The difference was statistically significant $(\mathrm{P}<0.05)$.

TABLE I. COMPARISON OF MEAN SCORES ACROSS OUTCOME MEASURES FOR GROUP A VERSUS GROUP B ( $\overline{\mathrm{X}} \pm \mathrm{s})$

\begin{tabular}{ccccc}
\hline & $\begin{array}{c}\text { group A's (n=32) Mean } \\
\text { Score }\end{array}$ & $\begin{array}{c}\text { group B's (n=32) Mean } \\
\text { Score }\end{array}$ & t & P-value \\
\hline objective scores & $43.72 \pm 3.58$ & $36.91 \pm 3.15$ & 8.09 & $<0.001$ \\
subjective scores & $39.50 \pm 1.81$ & $33.814 \pm 2.33$ & 10.88 & $<0.001$ \\
total scores of theoretical test & $83.22 \pm 3.75$ & $70.72 \pm 3.95$ & 12.99 & $<0.001$ \\
test scores of the experiment & $94.28 \pm 2.20$ & $85.44 \pm 3.52$ & 12.05 & $<0.001$ \\
\hline course & & & & \\
\hline
\end{tabular}

In the qualitative outcomes, the questionnaire results between the two groups were significantly different $(\mathrm{P}<$ 0.05). (Table 2).Compared to traditional curriculum, PBL combined with Sps were more effective at addressing the following learning objectives: improving ability of learning motivation and comprehensive analysis, facilitating good discussions.

TABLE II. COMPARISON OF STUdENTS’ PeRSONAL OPINIONFOR GROUP A VERSUS GROUP B（N，\%）

\begin{tabular}{|c|c|c|c|c|c|}
\hline & options & group A $(n=32)$ & $\operatorname{group} B(n=32)$ & $\chi^{2}$ & P-value \\
\hline To improve my & strongly agree & $19(59.4 \%)$ & $7(21.9 \%)$ & & \\
\hline ability to work & agree & $9(28.1 \%)$ & $7(21.9 \%)$ & 14.70 & 0.001 \\
\hline together as a team & strongly disagree & $4(12.5 \%)$ & $18(56.2 \%)$ & & \\
\hline \multirow{3}{*}{$\begin{array}{c}\text { To improve my } \\
\text { innovative ability }\end{array}$} & strongly agree & $20(62.5 \%)$ & $5(15.6 \%)$ & \multirow{3}{*}{15.23} & \multirow{3}{*}{0.000} \\
\hline & agree & $7(21.9 \%)$ & $19(59.4 \%)$ & & \\
\hline & strongly disagree & $5(15.6 \%)$ & $8(25.0 \%)$ & & \\
\hline \multirow{3}{*}{$\begin{array}{l}\text { To improve my } \\
\text { ability of } \\
\text { comprehensive } \\
\text { analysis }\end{array}$} & strongly agree & $22(68.8 \%)$ & $11(34.4 \%)$ & \multirow{3}{*}{10.50} & \multirow{3}{*}{0.005} \\
\hline & agree & $9(28.1 \%)$ & $12(37.5 \%)$ & & \\
\hline & strongly disagree & $1(3.1 \%)$ & $9(28.1 \%)$ & & \\
\hline to improve my & strongly agree & $21(65.6 \%)$ & $5(15.6 \%)$ & & \\
\hline problem-solving & agree & $10(31.2 \%)$ & $16(50.0 \%)$ & 19.56 & 0.000 \\
\hline abilities & strongly disagree & $1(3.1 \%)$ & $11(34.4 \%)$ & & \\
\hline \multirow{3}{*}{$\begin{array}{c}\text { To improve my } \\
\text { ability to practice }\end{array}$} & strongly agree & $23(71.9 \%)$ & $11(34.4 \%)$ & \multirow{3}{*}{14.25} & \multirow{3}{*}{0.001} \\
\hline & agree & $7(21.9 \%)$ & $6(18.8 \%)$ & & \\
\hline & strongly disagree & $2(6.2 \%)$ & $15(46.9 \%)$ & & \\
\hline
\end{tabular}




\section{DISCUSSION}

In recent years, researchers have adopted PBL teaching mode, which has covered all disciplines of medicine, including basic medicine, clinical medicine, preventive medicine and evidence-based medicine[6]. The application of standardized patient teaching can solve the problems such as lack of medical resources, short clinic time, and uncooperative patients[7]. Through this kind of teaching method can make students establish rigorous work style, improve medical quality and professional quality[8].

This study is to evaluate learning outcomes associated with PBL combined with SPs in the teaching of ophthalmology. Across all four examination mean scores were significantly higher for students in the group A than for those in the group B. These findings suggest that PBL combined with Sps can be effectively incorporated into the teaching of ophthalmology to improve the teaching quality of this course as well as affective learning goals.

To ensure that student learning objectives are met, PBL combined with Sps course must be thoughtfully designed, evaluated, and modified as necessary. PBL combined with Sps have the added ability to enhance shared cognition among students in a group-learning. Enhanced learning outcomes are important because they are hypothesized to influence clinical behaviors during medical college and later when the student becomes an independent ophthalmologist. Using "PBL combined with SP" teaching mode in basic science of ophthalmology can highly improve students' learning enthusiasm and cultivate students' self-learning ability ,practice ability and ability of clinical analysis.

However, there are some main limitations. First of all,the data were cross-sectional, which did not allow us to assess within-person changes that might occur as students approach graduation. Second, there are still some situations where positive signs cannot be imitated, which can be improved by using the teaching of real patients.

\section{REFERENCES}

[1] Jin J, Bridges SM. Educational technologies in problem-based learning in health sciences education: a systematic review. J Med Internet Res. 2014;16(12):251

[2] Bergman EM, de Bruin AB, Herrler A, et al.Students' perceptions of anatomy across the undergraduate problem-based learning medical curriculum: a phenomenographical study. BMC Med Educ. 2013; 13:152.

[3] Bokken L, Vail Dalen, Rethans JJ. Performance-related stress symptoms in simulated patients. Med Educ. 2004; 38(10):1089-1094.

[4] Berg K, Blatt B, Lopreiato J, et al. Standardized patient assessment of medical student empathy: ethnicity and gender effects in a multi-institutional study. Acad Med. 2015; 90(1):105-11.

[5] Lockwood MD, Tucker-Potter S, Sargentini NJ.Curricular analysis of competency-based osteopathic medical education: application of a matrix for quality enhancement to a standardized patient encounter example. J Am Osteopath Assoc. 2009; 109(9):486-500.

[6] Cui HY, Liu D, Qu W, et al. Practice on the teaching mode of PBL in ophthalmology teaching. International Eye Science. 2014; 14(7):1303-1306.

[7] Wang BJ, Fu B, Meng L, et al. Application of standardized patient to inquisition teaching course and the training evaluation. Chinese Journal of Medical Education Research. 2010; 10(9):1377-1379.

[8] Zhang SS, Sun J. The application of simulated patient role play in the inquiry and the medical record writing teaching. Chinese Journal of Medical Education Research. 2014; 5(13):512-515. 